\title{
Asinos e equinos apresentam diferentes estratégias na obtenção do recurso feno independente de sua distribuição
}

Tâmara Duarte Borges ${ }^{[a]}$, Emília RL Barreto ${ }^{[b]}$, Pedro Henrique Esteves Trindade ${ }^{[b]}$, Fernanda Mendes Barussi ${ }^{[a]}$, Fernanda Zettel Bastos $^{[a]}$, Pedro Vicente Michelotto J[ ${ }^{[a]}$

\footnotetext{
[a] Pontifícia Universidade Católica do Paraná (PUCPR), Curitiba, PR, Brasil

[b] Universidade Estadual Paulista (UNESP), Jaboticabal, SP, Brasil
}

*Autor correspondente

e-mail: tamaratdb@hotmail.com

\section{Resumo}

Objetivou-se avaliar se a forma de distribuição da oferta de feno difere na capacidade de obtenção deste recurso entre equinos e asininos. Seis equinos e seis asininos adaptados em um piquete em comum (50 x $50 \mathrm{~m}$ ) foram avaliados durante quatro períodos de 30 minutos. Os registros comportamentais foram realizados por filmagem, de forma direta, focal e com rota de amostragem contínua. 0 recurso feno ( $2 \mathrm{~kg}$ ) foi disponibilizado em sacolas de feno posicionadas em mourões no centro do piquete, de forma que os animais obtivessem acesso por todos os lados em um raio de $1 \mathrm{~m}$ de distância. 0 tratamento 1 (T1) consistiu na oferta de somente um ponto de acesso ao recurso, com $2 \mathrm{~kg}$ de feno; e o tratamento 2 (T2), com oferta de dois pontos de feno com $1 \mathrm{~kg}$ cada um. Registrou-se a duração total (s) que cada animal obteve acesso ao recurso quando submetidos a T1 e T2. Os dados foram transformados para distribuição logarítmica e submetidos à análise de modelos mistos (GLM) utilizando o software SAS (versão 9.2). Foi considerado como efeito fixo o tratamento, o período de avaliação e a espécie. Obteve-se diferença significativa $(\mathrm{P}=0,0015)$ para a variável espécie, sendo que os equinos permaneceram em média 732,25 min $(5,97 \pm 0,21)$ e asininos $1000,47(6,96$ $\pm 0,19)$ min. As variáveis tratamento e período de avaliação não foram significativas $(P=0,22 ; P=0,48$, respectivamente). Conclui-se que a espécie animal foi um fator determinante para obtenção de acesso ao recurso, que pode ser explicado por uma possível facilitação social entre os asininos e/ou uma a forte hierarquia de dominância entre os equinos. Isso sugere-nos que asininos e equinos apresentam diferentes estratégias na obtenção do recurso feno independente de sua distribuição.

Palavras-chave: Cavalos. Comportamento social. Etologia. 